\title{
SIKLON TROPIS WASHI DAN PENGARUHNYA TERHADAP SEBARAN HUJAN DI INDONESIA
}

\author{
Enwin Mulyana*
}

\begin{abstract}
Intisari
Siklon Tropis Washi yang menghantam Pulau Mindanao Filipina selatan pada $14-18$ Desember 2011 merupakan siklon paling mematikan di dunia yang terjadi pada tahun 2011. banjir bandang dan tanah longsor di Putu 10 jam pada tanggal 16 Desember 2011 memicu kerugian material sangat besar. TC Washi Mindanao. Ribuan orang meninggal dengan Indonesia. Aliran masa udara ke arah pusat siklon maruhi pola konvergensi di wilayah konvergensi di wilayah sebelah utara Kalimantan. Di misi lain ITCZ di sepanjang Laut Jawa sampai dengan Nusa tenggara Ka memperkuat daerah mengakibatkan hujan lebat dengan cakupan sangat luas di daerah Konvergensi udara ini Indonesia merupakan daerah bebas dari lintasan siklon namun perlu diwasut. Walaupun terutama hujan ekstrim dan angin kencang yang berpotensi menimbulkan efeknya hidrometeorologi.
\end{abstract}

\begin{abstract}
The deadly Tropical Cyclone Washi hit Mindanao Island South Philippine on December 14 flash flood and mudslides. The deaths $200 \mathrm{~mm}$ in 10 hours on December 16, causing multiple the deadliest storm of 2011. TC Washi offere than 1,000 residents making TC Washi is Indonesia. The airflow toward the center of the che atmospheric convergence pattern over area northern of Kalimantan. On the other hand TC Washi strengthen the the Java Sea to the Nusa tenggara. This atmospheric convergence caused heavy rain with the effect of tropical Cyclone effect such as
\end{abstract}

Kata kunci : tropical cyclone Washi, flash flood, rainfall, wind, bencana hidrometeorologi

\section{PENDAHULUAN}

Siklon Tropis Washi (selanjutnya akan disebut TC Washi) yang menerjang wilayah Mindanao Filipina Selatan tanggal 16 Desember 2011 mengakibatkan hujan sangat deras di wilayah tersebut. Hujan ekstrim selama kurang lebih 10 jam memicu banjir hebat di sebagian besar wilayah Mindanao. Beberapa daerah mengalami hujan dengan intensitas lebih dari 200 $\mathrm{mm}$ dalam waktu 10 jam. Akibatnya sungai tidak dapat menampung air hujan yang turun sangat deras, banjir terjadi di mana-mana membawa material dan menerjang semua benda yang ada di depannya. Rumah hancur, mobil dan manusia hanyut diterjang banjir. Banjir dan tanah longsor menghancurkan rumah di sepanjang daerah pegunungan. Di beberapa daerah, ketinggian air meningkat sekitar 3 meter dalam waktu kurang dari satu jam. Selain banjir, pada saat yang bersamaan angin sangat kencang dengan kecepatan $90 \mathrm{~km} / \mathrm{jam}$ menerbangkan atap rumah. Kondisi ini terus berlangsung dalam beberapa hari selama TC Washi melintas di wilayah Filipina. Lebih dari seribu orang meninggal/hilang (http:// internasional.kompas.com/read/2011/12/20/ $\begin{array}{llllllll}1 & 1 & 0 & 0 & 5 & 2 & 5 & 6\end{array}$ Badai.Washi.Sudah.Tewaskan.1000.Orang). Ribuan bangunan dan kendaraan rusak akibat badai ini. TC Washi merupakan siklon tropis dengan katagori paling mematikan di dunia yang terjadi pada tahun
2011 .

TC Washi yang terjadi pada bulan Desember adalah bukan merupakan puncak musim siklon di wilayah Samudra Pasifik bagian barat. Berdasarkan 
data dari Joint Typhoon Warning System (JTWC) selama tahun 1959-2011, rata-rata jumlah siklon tropis tertinggi di wilayahPasifik bagian barat terjadi pada bulan Agustus sedangkan jumlah terendah terjadi pada bulan Januari. Peningkatan jumlah siklon tropis mulai terjadi pada bulan Mei. Kondisi ini terus meningkat hingga mencapai puncaknya pada bulan Agustus. Setelah itu frekuensi munculan siklon tropis terus menurun hingga bulan Desember.

TC Washi diawali dengan munculnya pusat tekanan rendah di Samudera Pasifik sebelah timur Filipina pada tanggal 12 Desember 2011. Sehari kemudian pusat tekanan rendah tersebut dengan cepat menguat menjadi tropical depression (kecepatan angin d" 33 knot). Pada tanggal 14 Desember tropical depression tersebut semakin menguat menjadi tropical storm (34-63knot). Badai tersebut terus menguat menjadi tropical cyclon ( $\mathrm{e}^{\text {" }}$ 64 knot ) dan diberi nama TC Washi.

Wilayah Indonesia berada di daerah khatulistiwa dimana faktor coriolis muka bumi kecil sehingga tidak akan dilalui oleh siklon tropis tetapi masih menerima dampaknya. Siklon tropis yang terjadi di sekitar Samudra Pasifik sekitar Filipina maupun di Samudera Hindia sebelah selatan JawaNusa Tenggara, pengaruhnya cukup besar terhadap intensitas hujan di Indonesia. Siklon tropis yang terjadi di Filipina semakin meningkat ketika terjadi EI Nino, sebaliknya semakin berkurang ketika terjadi La Nina (Bradfield dan Suzana J., 2009). Fenomena yang sama juga disampaikan oleh Elsner dan Liu (2003).

Tulisan ini mencoba menyajikan informasi tentang TC Washi serta sebaran hujan yang terjadi di wilayah Indonesia pada saat siklon tersebut melintasi Filipina. Diharapkan hasil kajian ini dapat meningkatkan kewaspadaan terhadap potensi bencana meteorologi yang berhubungan dengan keberadaan siklon tropis di sekitar wilayah Indonesia.

\section{DATA}

Data yang digunakan dalam tulisan ini adalah data harian satelit TRMM (Tropical Rain Measurment Mission) 3B42, Citra Satelit GSM, tekanan udara level permukaan laut, angin gradient. Serta lintasan pergerakan TC Washi dari mulai munculnya pusat tekanan rendah di Pasifik Barat sebelah timur Filipina hingga TC Washi mulai melemah di Laut China Selatan.

\section{HASIL DAN PEMBAHASAN}

\subsection{TC Washi}

Pada tanggal 12 Desember 2011 muncul pusat tekanan rendah di Samudra Pasifik sebelah timur Filipina. Sehari kemudian pusat tekanan rendah

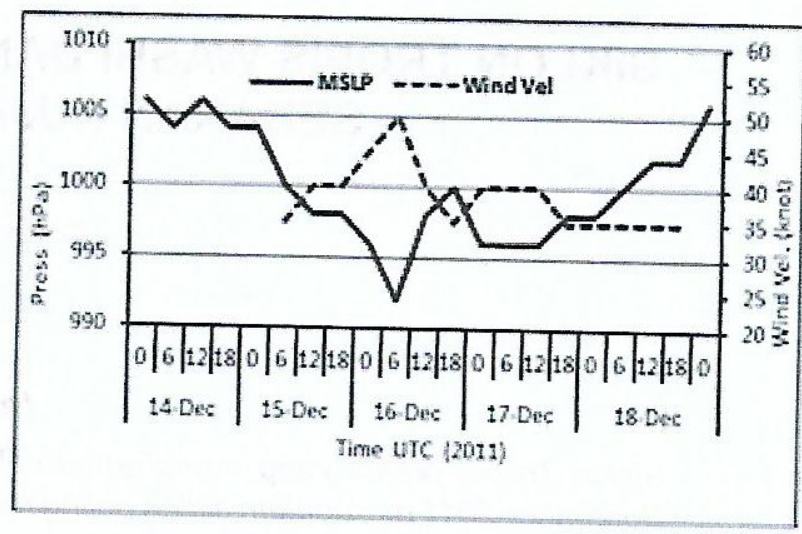

Gambar 1. Grafik tekanan udara permukaan dan kecepatan angin TC Washi.

tersebut dengan cepat menguat menjadi tropical depression (kecepatan angin $\left.\mathrm{d}^{\mathrm{TM}} 33 \mathrm{knot}\right)$. Tanggal 14 Desember tropical depression tersebut terus menguat menjadi tropical storm (34-63 knot). Badai tersebut terus menguat menjadi tropical cyclon ( $\mathrm{e}^{\mathrm{TM}}$ $64 \mathrm{knot}$ ) dan diberi nama TC Washi. Grafik tekanan udara dan kecepatan angin TC Washi dari tanggal 14 Desember sampai dengan 18 Desember 2011 diperlihatkan pada Gambar 1. Dari gambar tersebut terlihat pada tanggal 16 Desember terjadi penurunan tekanan udara serta peningkatan kecepatan angin yang sangat tajam.

Tangal 15 Desember TC Washi mulai masuk wilayah Filipina bagian selatan. Akibat terjangan tersebut beberapa wilayah di Filipina yang dilintasi TC Washi mengalami banjir dan longsor. Tanggal 17 Desember TC Washi mencapai Laut Cina Selatan dan akhirnya melemah menjadi depresi tropis pada tanggal 19 Desember 2011. Lintasan TC Washi sejak terbentuknya pusat tekanan rendah di sebelah timur Filipina, kemudian terbentuk TC Washi hingga

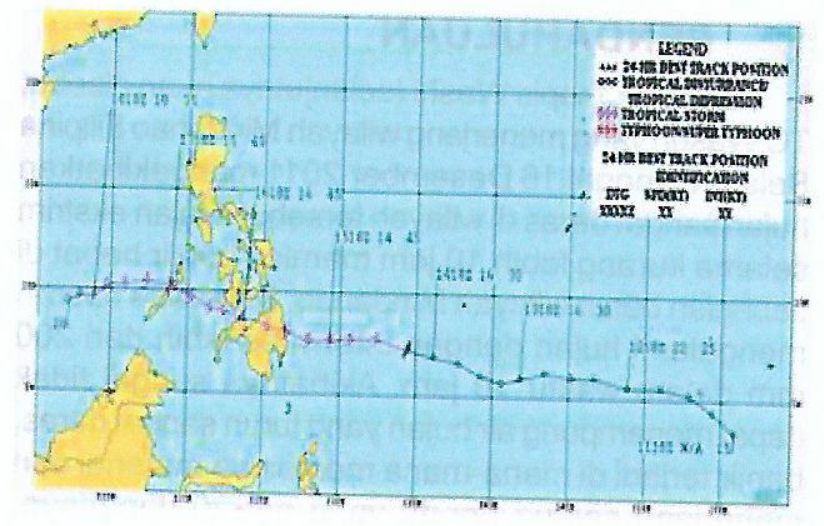

Gambar2. Lintasan TC Washi mulai dari munculnya pusat tekanan rendah di Samudra Pasifik sebelah timur Filipina hingga menghilang di Laut China Selatan. (Sumber: JWTC) 


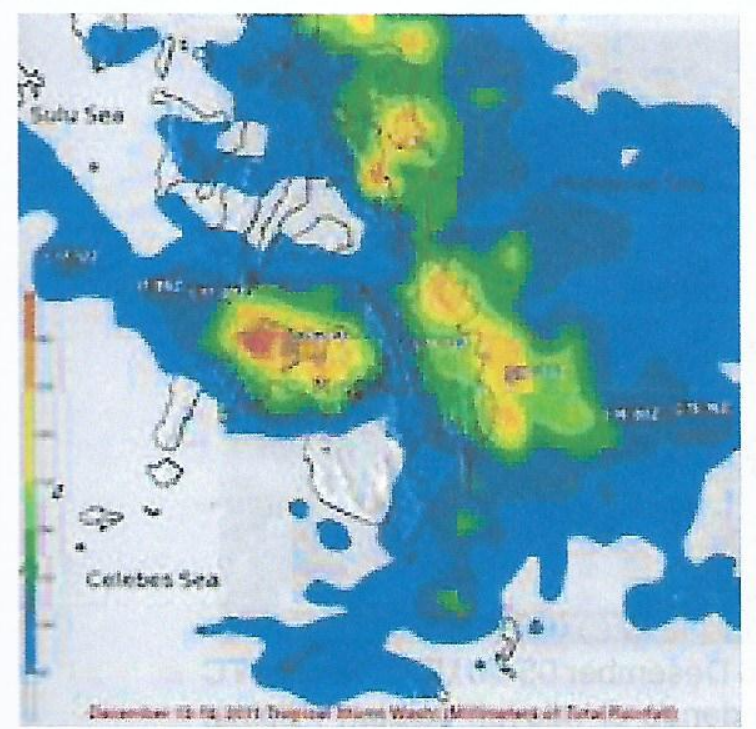

Gambar 3. Akumulasi hujan tanggal 13 s.d 19 Desember 2011 di wilayah Lintasan TC Washi. (Sumber : TRMM, NASA)

menghilang di Laut Cina Selatan diperlihatkan pada Gambar 2.

Berdasarkan satelit TRMM, selama terjadinya TC Washi, akumulasi hujan di wilayah Filipina Selatan terkonsentrasi di Pulau Mindanau seperti ditunjukkan pada Gambar 3. Intensitas hujan tanggal 13-19 Desember 2011 di wilayah Mindanau mencapai lebih dari $400 \mathrm{~mm}$. Konsentrasi hujan berada di wilayah timur dan barat Pulau Mindanau. Rata rata hujan pada area $7-9$ lintang utara dan $123-125$ bujur timur mulai tanggal 13 sampai dengan tanggal 19 Desember 2011 diperlihatkan pada Gambar 4. Dari gambar 4 dapat dilihat bahwa hujan mulai terjadi pada tanggal

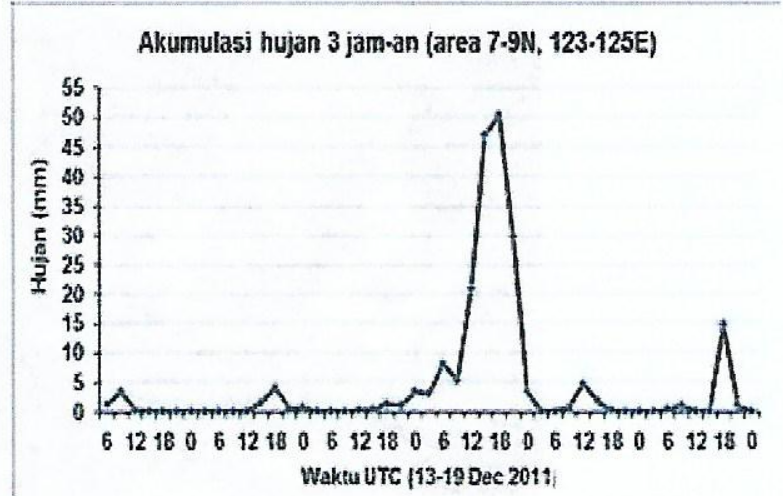

Gambar 4. Intensitas hujan TRMM per 3 jam dari tanggal 13 s.d 19 Desember $2011 \mathrm{di}$ area $7^{\circ}-9^{\circ} \mathrm{N}$ dan $123^{\circ}-125^{\circ} \mathrm{E}$.

16 Desember pagi. Hujan terus berlangsung hingga malam hari. Pada tengah malam tanggal 16 Desember mulai terjadi lonjakan intensitas hujan yang sangat tajam. Hujan ekstrim inilah yang memicu terjadinya banjir hebat dan tanah longsor di pulau Mindanao.

Gambar 5 merupakan kondisi atmosfer tanggal 15 Desember, sesaat sebelum TC Washi melintas Filipina yang termonitor oleh satelit TRMM. Ketika satelit melintas di atas TC Washi pada tanggal 15 Desember 2011 jam 1515 UTC, hujan lebat menyebar di sekeliling pusat siklon. Ketinggian puncak awan mencapai lebih dari $15 \mathrm{~km}$. dengan kecepatan angin mencapai 50 knot serta diameter siklon mencapai $160 \mathrm{~km}$. Siklon tersebut terus bergerak ke barat hingga barat laut dengan kecepatan 13 knot.

Pada tanggal 17 Desember, walaupun pusat siklon sudah melintasi Pulau Mindanao dan berada

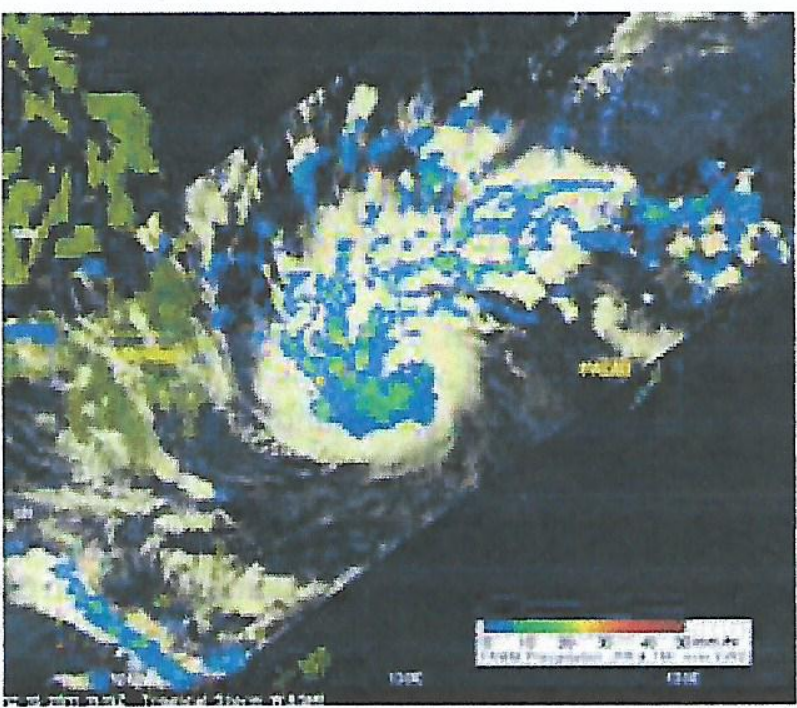

Gambar 5. Citra satelit TRMM tanggal 15 Desember 2011 yang menunjukkan gambaran 3 dimensi (kiri) dan sebaran awan (kanan). Hujan ringan hingga sedang diperlihatkan dengan warna hijau hingga biru. Sementara warna merah menunjukkan hujan dengan intensitas lebat. (Sumber: SSAI/ NASA, Hal Pierce) 


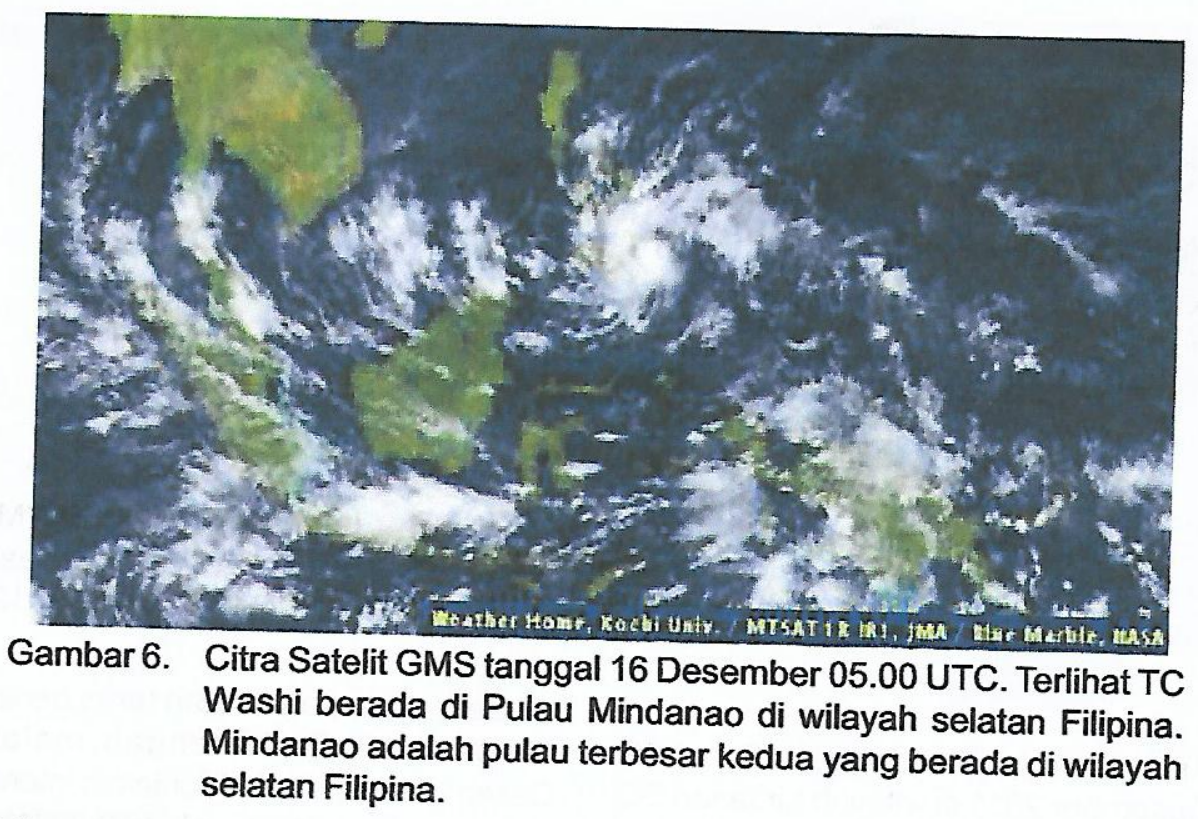

di Laut Cina Selatan, namun hujan lebat masih terjadi di hampir seluruh wilayah Filipina. Tanggal 18 Desember TC Washi semakin menjauh dari Filipina dan terus bergerak ke arah barat, hujan lebat masih terjadi di wilayah Filipina bagian barat laut. Tanggal 19 Desember TC Washi semakin mendekati wilayah Vietnam akan tetapi kekuatannya semakin melemah, dan akhirnya menghilang di Laut Cina Selatan. Berdasarkan citra satelit GMS, terlihat awan di utara Kalimantan bergerak ke arah pusat TC Washi. Sementara itu awan yang berada di selatan equator bergerak ke arah timur seperti diperlihatkan pada Gambar 6.

\subsection{Hujan di Wilayah Indonesia}

Aldrian dan Susanto (2003) membagi iklim di Indonesia menjadi 3 macam yaitu pola monsoon, pola ekuatorial dan pola lokal. Dari ke tiga pola iklim tersebut, curah hujan pada bulan Desember masih tinggi hampir di seluruh wilayah Indonesia kecuali di Maluku dan Irian.. Dalam bulan ini pola monsun Asia dominan di bagian barat Indonesia hingga Sulawesi selatan.

Sebaran hujan di wilayah Indonesia saat terjadinya TC Washi akan diulas berikut ini. Pada tanggal 15 Desember menjelang TC Washi masuk ke wilayah Filipina, hampir di seluruh wilayah Indonesai terjadi,hujan kecuali di sebagian Sumatera, Kalimantan, Sulawesi dan Maluku. Intensitas curah hujan bervariasi mulai dari $5 \mathrm{~mm}$ sampai dengan 60 $\mathrm{mm} /$ hari. Sebaran dan intensitas hujan di Wilayah Indonesia sehari sebelum TC Washi menerjang Filipina di sajikan dalam Gambar 7.

Dari pola angin yang disajikan pada Gambar 8 terlihat bahwa aliran massa udara dominan dari Asia dengan lokasi ITCZ berada di selatan ekuator,

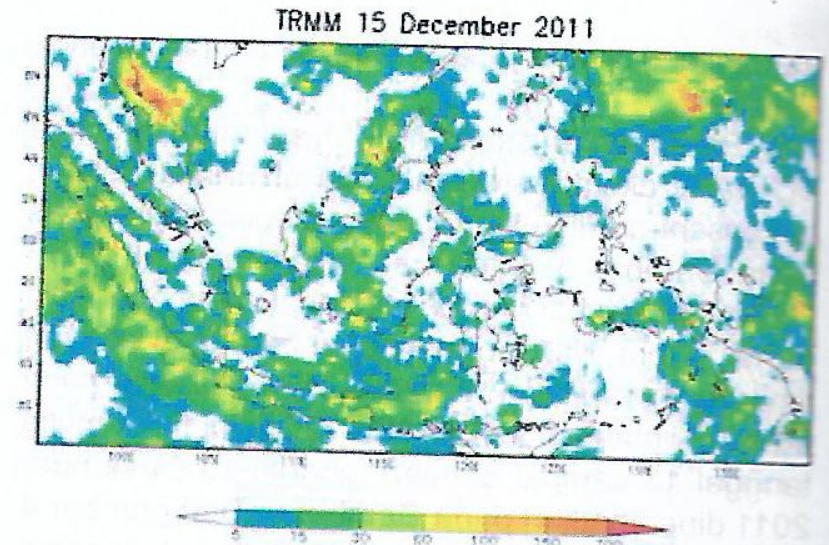

Gambar 7. Sebaran hujan tanggal 15 Desember 2011 di wilayah Indonesia sehari sebelum TC Washi menerjang Filipina.

memanjang mulai Laut Jawa sampai Nusa Tenggara. Kecuali Nusa Tenggara, maka seluruh wilayah Indonesia dipengaruhi oleh monsun Asia. TC Washi juga terlihat mempengaruhi pola monsoon di wilayah Indonesia, dari Gambar tersebut terlihat aliran udara dari Laut China Selatan mengalir masuk menuju ke pusat TC Washi yang berada di Filipina.

Sehari kemudian, yaitu tanggal 16 Desember ketika TC Washi menerjang pulau Mindanao, intensitas hujan di wilayah Indonesia terus meningkat terutama di Jawa, Nusa Tenggara Laut Jawa hingga Kalimantan dan Sulawesi. Perubahan pola angin akibat pengaruh TC Washi memperkuat daerah konvegensi di perairan antara Kalimantan, Jawa dan Nusa Tenggara. Intensitas hujan di daerah tersebut mencapai $100 \mathrm{~mm} /$ hari seperti diperlihatkan pada Gambar 9.

Tanggal 17 Desember ketika T C Washi sudah melewati pulau Mindanau, daerah konvergensi di 


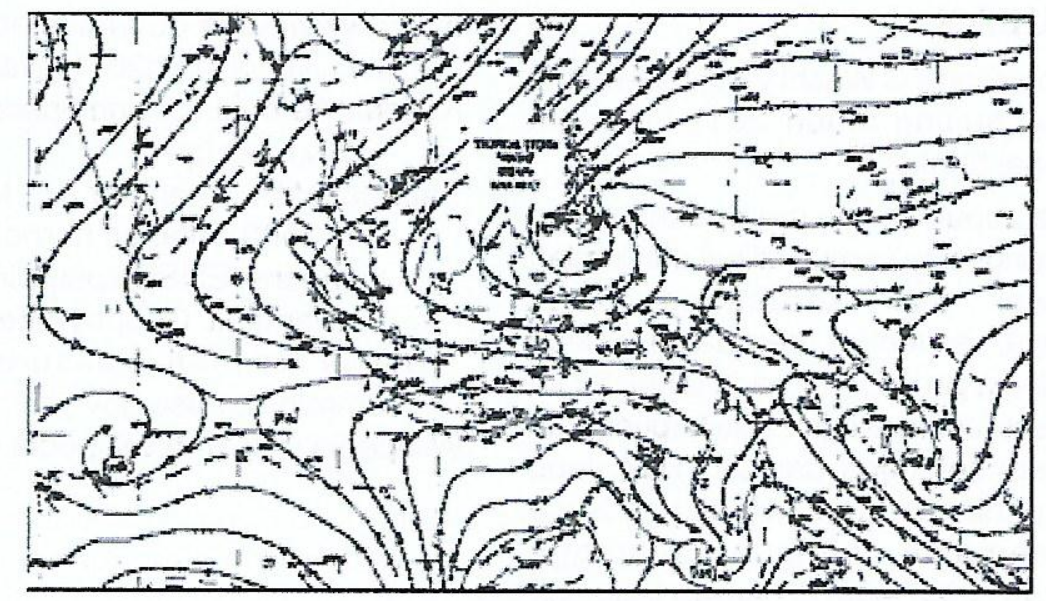

Gambar 8. Gradient wind tgl 15 Desember 2011 yang menunjukkan aliran udara di wilayah Indonesia dan sekitarnya pada saat terjadi TC Washi.

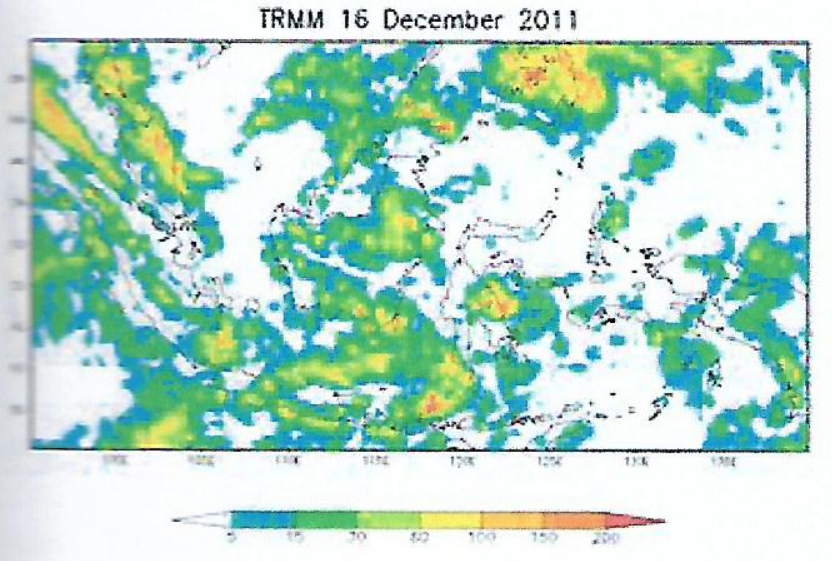

Gambar 9. Sebaran hujan tanggal 16 Desember 2011 di wilayah Indonesia saat TC Washi menerjang pulau Mindanao, Filipina Selatan.

sekitar Jawa semakin meluas dan membentuk hujan dengan intensitas lebih dari $100 \mathrm{~mm} /$ hari. Selain itu daerah pembentukan awan di laut Cina Selatan sebelah utara Kalimantan semakin meluas serta hujan yang terjadi intensitasnya juga sangat tinggi. Sedangkan Sulawesi dan Maluku hujannya sangat minim. Sebaran hujan tanggal 17 Desember ditunjukkan pada gambar 10.

Tanggal 18 Desember ketika TC Washi berada di Laut Cina Selatan sebelah utara Kalimantan, curah hujan di wilayah Indonesia masih tinggi dengan sebaran yang sangat luas. Dari Gambar 11 terlihat ada peningkatan hujan di Kalimantan bagian utara serta di Laut Cina Selatan. Kondisi tersebut kemungkinan akibat pola konvergensi di daerah tersebut terkait dengan posisi TC Washi di Laut China Selatan. Sementara daerah hujan akibat konvergensi di perairan antara Kalimantan dan Nusa tenggara lebih cenderung karena pengauh ITCZ.

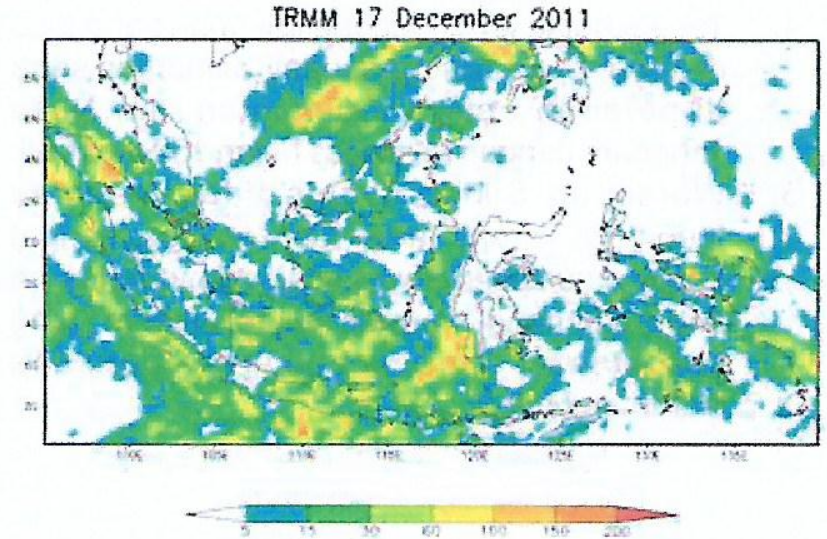

Gambar 10. Sebaran hujan tanggal 17 Desember 2011 di wilayah Indonesia saat TC Washi sudah melewati Pulau Mindanao.

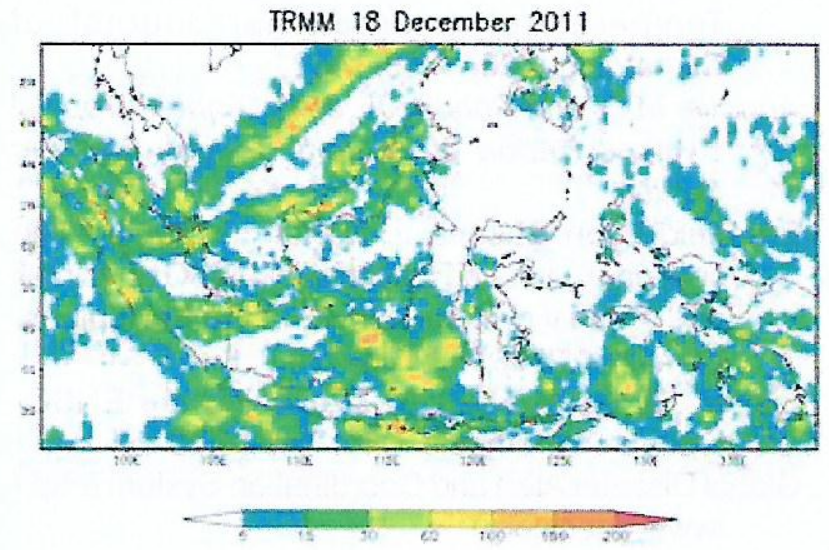

Gambar 11. Sebaran hujan tanggal 18 Desember 2011 di wilayah Indonesia saat TC Washi berada di Laut Cina Selatan. 


\section{KESIMPULAN}

Dari kajian tentang TC Washi yang menerjang Filipina pada penghujung tahun 2011 ini dapat disimpulkan sebagai berikut :

1. TC Washi walaupun bukan merupakan siklon tropis yang paling kuat, namun dilihat dari jumlah korban jiwa dan kerusakan yang ditimbulkannya, siklon ini merupakan Siklon paling mematikan yang terjadi pada tahun 2011.

2. Pola konvergensi udara di Indonesia terpengaruh oleh TC Washi sehingga daerah ITCZ yang berada di sepanjang Laut Jawa hingga Nusa Tenggara semakin menguat sehingga mengakibatkan hujan lebat di daerah tersebut.

3. Aliran udara bergerak masuk ke pusat TC Washi dan membentuk daerah konvergensi di sekitar Kalimantan bagian utara hingga ke laut Cina Selatan.

4. Terjadi hujan lebat dengan cakupan yang luas di Jawa, Nusa Tenggara dan Kalimantan serta di perairan antara Kalimantan dan Nusa Tenggara dengan intensitas hujan $100 \mathrm{~mm} / \mathrm{hari}$.

5. Walaupun Siklon Tropis tidak melintas Indonesia karena faktor Coriolis yang sangat kecil, namun perlu diwaspadai efeknya terutama angin kencang maupun hujan ekstrim yang berpotensi menimbulkan bencana hidrometeorologi.

\section{DAFTAR PUSTAKA}

Aldrian, E. and , R.D. Susanto, 2003, : Indentification of the Three Dominant Rainfall Regions within Indonesia and their Relationship to Sea Surface Temperature, International Journal of Climatology, 23, 1435-1452.

Angove. M.D, and Robert. JF. 2012 :Annual Tropical Cyclone Report 2011. Joint Typoon Warning Center

Bradfield Lyon Suzana J. Camargo, 2009 : The seasonally-varying influence of ENSO on rainfall and tropical cyclone activity in the Philippines, Clim Dyn (2009) 32:125-141.

Elsner JB, Liu K-b (2003) Examining the ENSOtyphoon hypothesis. Clim Res 25:43-54

Global Disaster Alert and Coordination System (http:/ /www.gdacs.org)

http://www.nasa.gov/mission_pages/hurricanes/ archives/2011/h2011_Washi.html

http://internasional.kompas.com/read/2011/12/20/ 11005256/Badai.Washi.Sudah.Tewaskan.1.00 0.Orang http://www.nasa.gov/mission_pages/hurricanes/ archives/2011/h2011_Washi_prt.htm

National Aeronautics and Space Administration (http:/ (www.nasa.gov)

Saunders MA, Chandler RE, Merchant CJ, Roberts FP (2000) Atlantic hurricanes and NW Pacific typhoons: ENSO spatial impacts on occurrence and landfall. Geophys Res Lett 27:1147-1150.

Tropical Rainfall Measuring Mission (http:// trmm.gsfc.nasa.gov/)

Wikipedia (http://en.wikipedia.org) 